\title{
Elemental uptake via immersion: a mass-marking technique for the early life-history stages of cephalopods
}

\author{
Nicholas L. Payne ${ }^{1,3, *}$, Jayson M. Semmens ${ }^{2}$, Bronwyn M. Gillanders ${ }^{1}$ \\ ${ }^{1}$ Southern Seas Ecology Laboratories, University of Adelaide, South Australia 5005, Australia \\ ${ }^{2}$ Tasmanian Aquaculture \& Fisheries Institute, University of Tasmania, Tasmania 7001, Australia \\ ${ }^{3}$ School of Biological, Earth and Environmental Sciences, University of NSW, New South Wales 2052, Australia
}

\begin{abstract}
Despite the ecological and increasing commercial significance of cephalopods worldwide, little attention has been paid to developing techniques that investigate the movement of early life-history stages. We evaluated the potential of mass-marking giant Australian cuttlefish Sepia apama hatchlings, via immersion of eggs in water enriched in ${ }^{137} \mathrm{Ba}$ isotope. Eggs were immersed in several ${ }^{137} \mathrm{Ba}$ concentrations, for varying durations, and at different stages of development. Statoliths of hatchlings from each combination of ${ }^{137} \mathrm{Ba}$ concentration $\left(0.3\right.$ and $\left.1 \mathrm{\mu g} \mathrm{l}^{-1}\right)$ and immersion time $(2$, 5 and 8 d) produced lower mean ${ }^{138} \mathrm{Ba}:{ }^{137} \mathrm{Ba}$ values than control hatchlings, and mark success was generally high $(70-100 \%$ of statoliths were unequivocally marked across all treatments). Development stage was an important factor, with statoliths successfully marked only for eggs immersed in ${ }^{137} \mathrm{Ba}$ at $10 \mathrm{wk}$ of age. These results suggest that marking of statoliths via enriched isotope immersion offers considerable potential for understanding juvenile dispersal and connectivity of cephalopod populations in nature.
\end{abstract}

KEY WORDS: Enriched isotope $\cdot$ Connectivity $\cdot$ Otolith chemistry $\cdot$ ICP-MS $\cdot$ Cephalopods $\cdot$ Otolith chemistry $\cdot$ Markers $\cdot \mathrm{Mn} \cdot$ Otolith $\cdot$ Statolith $\cdot$ Barium

Resale or republication not permitted without written consent of the publisher

\section{INTRODUCTION}

The exchange of individuals among discrete, geographically separated regions is a critical property of marine ecosystems (Cowen et al. 2000, Thorrold et al. 2001), and quantifying the scales over which the larvae of marine organisms disperse is central to understanding population dynamics and the management and conservation of marine biodiversity (Jones et al. 2005). Quantifying rates of larval exchange has traditionally been extremely difficult, as the natal origins of adults in marine ecosystems are largely unknown (Jones et al. 1999, Thorrold et al. 2001). The development of new techniques that investigate the movement of early lifehistory stages of marine organisms is recognised as a high priority (Sale et al. 2005, Pecl et al. 2010), and for fishes, significant advances have been made in recent years.
Ontogenetic shifts in habitat use have been evaluated through the analysis of natural elemental signatures in fish otoliths (e.g. Gillanders 2002a, Gillanders \& Kingsford 2003), as the geochemical composition of otoliths is influenced by the chemical and physical composition of the animal's environment (Campana 1999, Elsdon et al. 2008). However, numerous source populations must be characterised (Gillanders 2002a), signatures may be temporally variable at a given location (Gillanders 2002b, Cowen \& Sponaugle 2009), and the physicochemical environments must be heterogeneous enough over spatial scales such that individuals from different locations can be identified (Elsdon et al. 2008). Each of these issues can create barriers to accurately elucidating ontogenetic movement information from natural otolith signatures (Elsdon et al. 2008).

Elemental marking of calcified structures has been recognised as a useful method of mass-marking fish for 
some years (Ennevor \& Beames 1993, Brown \& Harris 1995), with strontium the most commonly used element. However the large natural variability of Sr:Ca in water (Kraus \& Secor 2004) can necessitate large concentrations of $\mathrm{Sr}$, to ensure that marks cannot be mistaken for natural signatures. Enriched stable isotopes have emerged as an effective alternative, and have been shown to produce unequivocal marks in otoliths of several fish species (e.g. Thorrold et al. 2006, Munro et al. 2008, Williamson et al. 2009a).

The field application of mass-marking techniques (using both enriched stable isotopes and fluorescent compounds) has been successfully demonstrated for several fish species, where large numbers of juvenile fish have been marked in situ, and subsequent rates of dispersal quantified (e.g. Jones et al. 1999, Jones et al. 2005, Almany et al. 2007). For example, Almany et al. (2007) used stable barium isotopes to mark large numbers of 2 coral reef fish species in order to determine degrees of natal homing. Jones et al. (2005) successfully determined the natal origins of clownfish Amphiprion polymnus in Papua New Guinea by mass-marking the otoliths of larvae with tetracycline. Whilst significant advances have been made with respect to mass-marking early life-history stages of fish, little attention has been paid to cephalopods.

Cephalopods are present in all of the world's oceans (Boyle 1983), and play a variety of roles throughout global marine ecosystems (Rodhouse \& Nigmatullin 1996). Whilst several studies have examined natural elemental signatures in cephalopod statoliths (Arkhipkin et al. 2004, Zumholz et al. 2007, Warner et al. 2009), only one published study to date has specifically examined the potential of mass-marking techniques for the early life-history stage of cephalopods (Pecl et al. 2010). This study evaluated the potential of transgeneration isotopic labelling (TRAIL) for several cephalopod species. TRAIL relies on the maternal transfer of an enriched isotope from an injected female to the calcified structures of its developing offspring (Thorrold et al. 2006, Munro et al. 2009, Williamson et al. 2009a), and Pecl et al. (2010) found that the technique may not be suitable for all cephalopods. Therefore, alternative mass-marking techniques are crucial for understanding connectivity and dispersal of cephalopods.

From May to August each year, a unique breeding aggregation of giant Australian cuttlefish Sepia apama occurs in northern Spencer Gulf, South Australia, where more than 200000 mature animals converge on a highly localised area (60 ha) of rocky reef to breed. Whilst mating behaviour and processes of sexual selection are well studied in this species (Hall \& Hanlon 2002, Naud et al. 2004, Hanlon et al. 2005, Payne et al. $2010,2011 a, b)$, there is no information on the extent of juvenile dispersal or degree of natal homing in this species. The aim of this study was to evaluate the potential of enriched isotope $\left({ }^{137} \mathrm{Ba}\right)$ immersion for mass-marking $S$. apama statoliths. Our specific objectives were to examine the influence of (i) isotope concentration, (ii) immersion time, and (iii) the developmental stage at which eggs are immersed on the uptake of ${ }^{137} \mathrm{Ba}$ by the statoliths.

\section{MATERIALS AND METHODS}

Egg collection and experimental design. Sepia apama eggs were collected via SCUBA from the underside of shallow (approximately 2 to $3 \mathrm{~m}$ deep) rock ledges at breeding grounds near Point Lowly, northern Spencer Gulf, throughout July to August of 2007 and 2008 and transported to a controlled environment room at the University of Adelaide. Haphazardly-selected eggs were suspended in clutches of 12 beneath polystyrene floats to mimic their orientation in nature, and each clutch was assigned to a separate 51 tank. Temperature was adjusted to mimic the gradual increase experienced at Point Lowly from July to November (14 to $18^{\circ} \mathrm{C}$; Hall \& Fowler 2003), salinity was maintained at 38 , and a 12:12 h light:dark cycle was employed. Water quality parameters were maintained below critical limits for cuttlefish $\left(\mathrm{NH}_{4}<0.5 \mathrm{mg} \mathrm{l}^{-1}, \mathrm{NO}_{2}<0.2 \mathrm{mg} \mathrm{l}^{-1}\right.$, and $\mathrm{NO}_{3}<50 \mathrm{mg} \mathrm{l}^{-1}$; Hanley et al. 1998, Minton 2004) via manual water changes every 2 to $3 \mathrm{~d}$.

Experiment 1: isotope concentration and immersion time. The aim of this experiment was to determine the influence of concentration and immersion time on the uptake of ${ }^{137} \mathrm{Ba}$ into statoliths. Twelve eggs of a variety of developmental stages were haphazardly assigned to one of two ${ }^{137} \mathrm{Ba}$ concentrations (0.3 and $1 \mu \mathrm{g} \mathrm{l}^{-1}$ ) and one of 3 immersion times $(2,5$ and $8 \mathrm{~d})$. Two 51 replicate tanks were used for each treatment. A solution of known ${ }^{137} \mathrm{Ba}$ concentration was made by dissolving $\mathrm{BaCO}_{3}$ enriched in ${ }^{137} \mathrm{Ba}\left(81.9 \%{ }^{137} \mathrm{Ba}\right.$ and $17.4 \%{ }^{138} \mathrm{Ba}$; Oak Ridge National Laboratories) in ultrapure water and concentrated $\mathrm{HCl}$, and this was diluted once all carbonate had dissolved. The appropriate solution volumes were then pipetted into each tank in the last week of August 2007. The age of eggs was unknown at the time of immersion in ${ }^{137} \mathrm{Ba}$; however embryos were clearly visible within many egg capsules, with the majority of individuals falling within the mid- to lateterm macroscopic stages of development defined by Hall \& Fowler (2003), and few classified as young or early-term. A single water change was made halfway through the immersion times for the 5 and $8 \mathrm{~d}$ treatments, after which additional ${ }^{137}$ Ba solution was added to reach the desired concentration. After each immersion period, eggs were thoroughly rinsed and returned to normal seawater until hatching. Immediately after 
hatching, cuttlefish were killed in an ice/sea-water slurry, and frozen until analysis.

Experiment 2: developmental stage. The second experiment was aimed at determining the influence of development stage on the uptake of ${ }^{137} \mathrm{Ba}$ into statoliths. On 22 July 2008, eggs were collected within $1 \mathrm{~h}$ of being laid (oviposition was observed whilst on SCUBA, and eggs were immediately collected) and haphazardly allocated to a variety of developmental stage treatments, for immersion in enriched ${ }^{137} \mathrm{Ba}$ at $1,2,4,6$ and $10 \mathrm{wk}$ of age. Twelve eggs were allocated to each 51 tank, with 2 replicate tanks per treatment. The regime chosen for each treatment was $1 \mu \mathrm{g} \mathrm{l}^{-1}{ }^{137} \mathrm{Ba}$ and an immersion time of $2 \mathrm{~d}$. Following immersion at each life history stage, eggs were rinsed and returned to normal seawater until hatching. At hatching, cuttlefish were killed in an ice/seawater slurry and frozen until analysis.

Statolith preparation and isotope analysis. Statoliths were extracted from the animal, rinsed in ultrapure water, dried in a flume hood and stored in eppendorf tubes. For all experiments, either the right or left statolith was haphazardly selected from 5 individuals (which were also haphazardly selected) within each tank, and whole statoliths were mounted on glass microscope slides with double-sided adhesive tape. A thin layer of thermoplastic Crystalbond glue, spiked with 40 ppm indium to enable discrimination between the statolith and Crystalbond, was placed between the adhesive and glass slide.

Statoliths were analysed with a New Wave Nd Yag $213 \mathrm{~nm}$ UV laser connected to an Agilent 7500cs inductively coupled plasma-mass spectrometer (ICP-MS). Operating parameters for this system are shown in Table 1. The laser ablated through the core of the statolith lateral dome, thereby capturing growth throughout the life of the hatchling. The isotopes analysed were ${ }^{137} \mathrm{Ba}$, ${ }^{138} \mathrm{Ba}$ and ${ }^{55} \mathrm{Mn}$; while In was monitored to

Table 1. Sepia apama. Operating parameters of the New Wave Nd Yag $213 \mathrm{~nm}$ UV laser and Agilent 7500cs inductively coupled plasma mass spectrometer (ICP-MS) used to analyse the statoliths

\begin{tabular}{ll} 
Parameter & \\
\hline Laser & \\
Wavelength & $213 \mathrm{~nm}$ \\
Mode & $\mathrm{Q}-\mathrm{switched}$ \\
Frequency & $5 \mathrm{~Hz}$ \\
Spot size & $30 \mu \mathrm{m}$ \\
Laser power & $65 \%$ \\
Beam energy & $0.25-0.3 \mathrm{~mJ}$ \\
Carrier gas & $\mathrm{Ar}\left(0.7-0.921 \mathrm{~min}^{-1}\right)$ \\
ICP-MS: Agilent $\mathbf{7 5 0 0 c s}$ & \\
Optional gas & He $(55-60 \%)$ \\
Cone & Platinum \\
Dwell time & $300 \mathrm{~ms}$ \\
Detection modes & Pulse and analogue
\end{tabular}

ensure the laser had not ablated through the statolith and into the Crystalbond. To correct for mass bias and machine drift, a reference standard (NIST 612, National Institute of Standards and Technology) was analysed at the beginning and end of each session, and after every 8 to 10 statoliths. We assumed that the relative abundances of ${ }^{138} \mathrm{Ba}:{ }^{137} \mathrm{Ba}$ in the standard were the same as the relative natural abundances (6.38) based on the International Union of Pure and Applied Chemistry values of isotope abundances (Rosman \& Taylor 1998). Correction factors were then applied to the sample ratios following Munro et al. (2008). The ${ }^{138} \mathrm{Ba}:{ }^{137} \mathrm{Ba}$ data were smoothed by a 6-point running mean (following Sinclair et al. 1998), and the resulting minimum value across each statolith was used in subsequent analyses (following Munro et al. 2008, 2009).

Statistical analyses. For the first experiment, a 2-factor ANOVA was used to examine the effect of concentration and immersion time on ${ }^{138} \mathrm{Ba}:{ }^{137} \mathrm{Ba}$ in statoliths, with both concentration and immersion time treated as fixed factors. Data were not transformed as Cochran's $C$-test indicated homogeneous variances $(p>0.05)$. For the second experiment, a 1-factor ANOVA was used to compare ${ }^{138} \mathrm{Ba}:{ }^{137} \mathrm{Ba}$ between development stages. Variances remained heterogeneous despite transformation, so alpha was set at 0.01 for this analysis to reduce the probability of Type 1 error. We initially used 3-factor and 2-factor ANOVAs for Experiment 1 and 2, respectively, with tank included as a random factor for both analyses, but since the effect of tank was not significant in both instances ( $p$ $>0.05)$, data were pooled across tank and analysed by treatment. Least significant difference (LSD) post-hoc tests were used to compare mean ${ }^{138} \mathrm{Ba}:{ }^{137} \mathrm{Ba}$ between treatment groups and the control group for both experiments (each combination of concentration and immersion time were treated as individual groups in a 1-factor ANOVA with 7 levels for Experiment 1). As a measure of mark success, we set a successful mark criterion of 5.89, which is the mean ${ }^{138} \mathrm{Ba}:{ }^{137} \mathrm{Ba}$ of the control group minus 3 standard deviations (following Almany et al. 2007). If ${ }^{138} \mathrm{Ba}:{ }^{137} \mathrm{Ba}$ of an individual was less than this value, it was considered marked.

\section{RESULTS}

\section{Experiment 1: isotope concentration and immersion time}

The first individual hatched on 21 September, and all viable eggs had hatched by 6 November, representing a hatching period of $47 \mathrm{~d}$. Assuming a 16-wk mean development period (as was the case in Experiment 2), then eggs were immersed in enriched ${ }^{137} \mathrm{Ba}$ at between approximately i.e. Weeks 6 and 13 (i.e. 40 to $90 \%$ ) of 
the development period. Cuttlefish hatchlings from eggs immersed in water enriched with ${ }^{137} \mathrm{Ba}$ displayed ${ }^{138} \mathrm{Ba}:{ }^{137} \mathrm{Ba}$ profiles that differed from those of control hatchlings. Profiles of statoliths from control hatchlings displayed relatively constant ${ }^{138} \mathrm{Ba}:{ }^{137} \mathrm{Ba}$ throughout the statolith lateral dome, and this ratio was generally close to the expected value of 6.38 (Fig. 1a). However, for hatchlings immersed in enriched ${ }^{137} \mathrm{Ba}$, statoliths displayed a marked decrease in ${ }^{138} \mathrm{Ba}:{ }^{137} \mathrm{Ba}$, with lower ratios on either side of the nucleus of the lateral dome (Fig. 1b). For both treatment and control statoliths, a characteristic peak in Mn concentration was seen in the nucleus (assuming the nucleus was reached approximately half-way through the ablation duration), as has been reported for fish (Fig. 1a,b).

A significant interaction was detected between concentration and immersion time (Table 2a), so separate

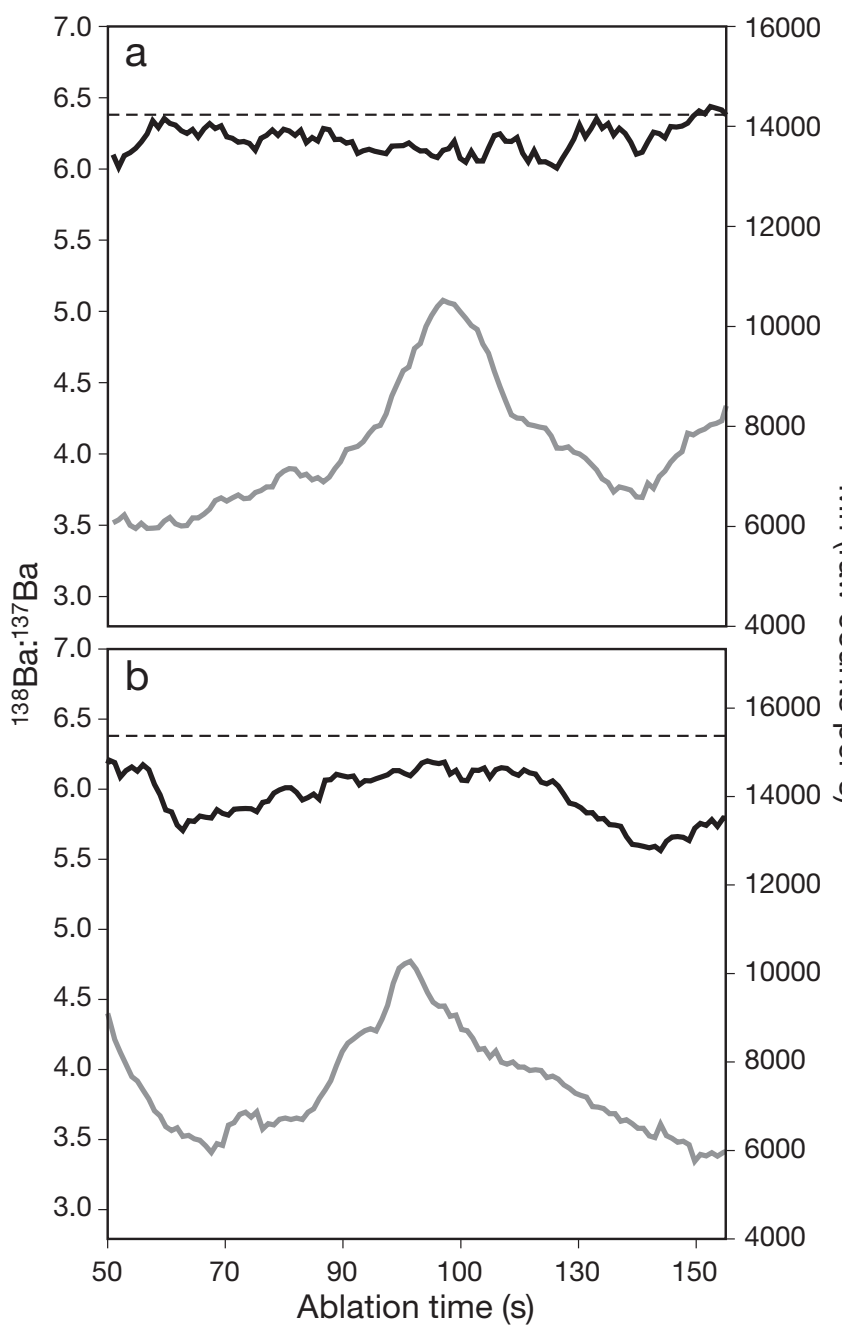

Fig. 1. Sepia apama. Profiles of ${ }^{138} \mathrm{Ba}:{ }^{137} \mathrm{Ba}$ (black lines) and Mn concentration (indicating the position of the lateral dome nucleus; grey lines) in statoliths of hatchlings (a) reared in nor-

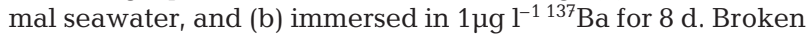
horizontal line represents the natural ${ }^{138} \mathrm{Ba}:{ }^{137} \mathrm{Ba}$ ratio
Table 2. Sepia apama. Analysis of variance comparing ${ }^{138} \mathrm{Ba}:{ }^{137} \mathrm{Ba}$ ratios in statoliths: (a) immersed in enriched bar-

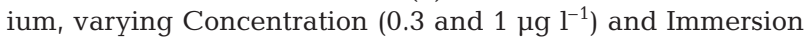
time $(2,5$ and $8 \mathrm{~d}) ;(\mathrm{b})$ immersed in enriched barium $\left(1 \mu \mathrm{g} \mathrm{l}^{-1}\right.$ ${ }^{137} \mathrm{Ba}$ for $2 \mathrm{~d}$ ) at varying stages of development $(1,2,4,6$ and 10 wk of age). Significant p-values are shown in bold

\begin{tabular}{|c|c|c|c|c|}
\hline & $\mathrm{df}$ & MS & $F$ & $\mathrm{p}$ \\
\hline \multicolumn{5}{|l|}{ (a) } \\
\hline Immersion time & 2 & 0.998 & 2.283 & 0.112 \\
\hline Concentration & 1 & 1.824 & 4.172 & 0.046 \\
\hline $\begin{array}{l}\text { Immersion time } \times \\
\text { Concentration }\end{array}$ & 2 & 3.170 & 7.253 & 0.002 \\
\hline $\begin{array}{l}\text { Residual } \\
\text { (b) }\end{array}$ & 54 & 0.437 & & \\
\hline Developmental stage & 5 & 0.418 & 103.936 & 0.000 \\
\hline Residual & 54 & 0.004 & & \\
\hline
\end{tabular}

1-way ANOVAs were undertaken for each of the 2 concentrations. Significant differences were not detected among immersion times for the $0.3 \mu \mathrm{g} \mathrm{l}^{-1}$ treatment $\left(F_{2,27}=1.82 ; \mathrm{p}>0.05\right)$, however ratios for the $2 \mathrm{~d}$ immersion period were significantly higher than the $8 \mathrm{~d}$ period for the $1 \mu \mathrm{g} \mathrm{l}^{-1}$ treatment $\left(F_{2,27}=7.36\right.$; LSD p $<$ 0.05). All combinations of concentration ( 0.3 and $1 \mu \mathrm{g}$ $\left.\mathrm{l}^{-1}\right)$ and immersion time $(2,5$, and $8 \mathrm{~d})$ produced lower mean ${ }^{138} \mathrm{Ba}:{ }^{137} \mathrm{Ba}$ ratios than for control hatchlings (i.e. those not immersed in water with enriched ${ }^{137} \mathrm{Ba}$; LSD $\mathrm{p}<0.05$; Fig. 2). Mark success was generally high for each combination of concentration and immersion time, with 80 to $90 \%$ of hatchlings successfully marked for the $0.3 \mu \mathrm{g} \mathrm{l}^{-1}$ treatments ( 26 of $\mathrm{n}=30$ ), and between 70 and $90 \%$ success for the $1 \mu \mathrm{g} \mathrm{l}^{-1}$ treatments (25 of $\mathrm{n}=30$; Fig. 2).

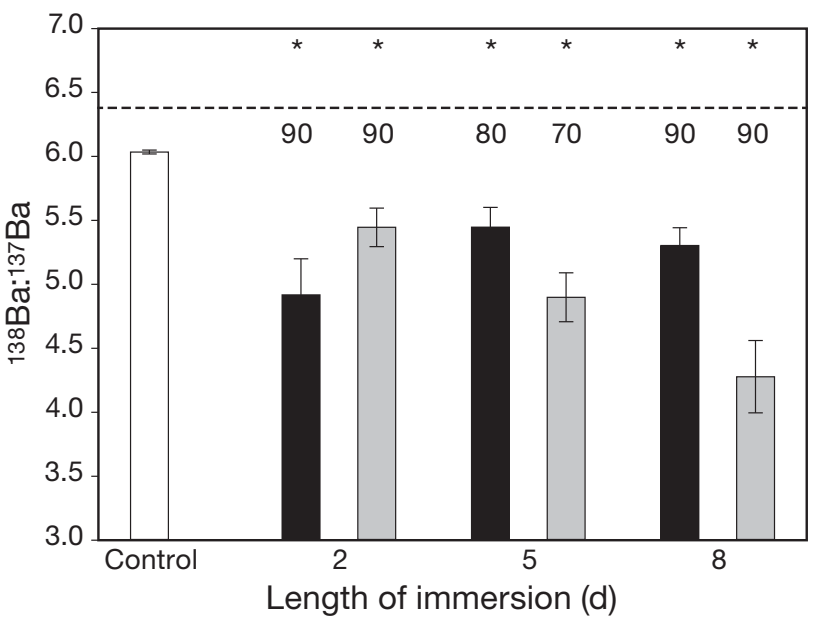

Fig. 2. Sepia apama. Comparison of mean $( \pm \mathrm{SE}){ }^{138} \mathrm{Ba}:{ }^{137} \mathrm{Ba}$ ratio in statoliths of hatchlings reared in water enriched in 0.3 (black bars) and $1 \mu \mathrm{g} \mathrm{l}^{-1}$ (grey bars) ${ }^{137} \mathrm{Ba}$ for 2, 5 and $8 \mathrm{~d}$. Asterisks indicate significant differences between treatment groups and the control group, labels indicate the percent of statoliths successfully marked per treatment, and the broken horizontal line represents the natural ${ }^{138} \mathrm{Ba}:{ }^{137} \mathrm{Ba}$ ratio 


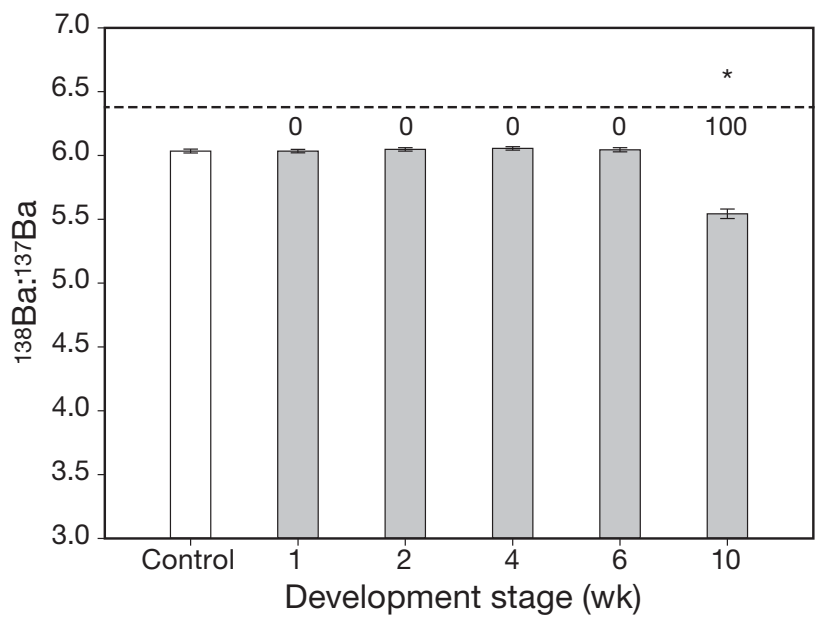

Fig. 3. Sepia apama. Comparison of mean $( \pm \mathrm{SE}){ }^{138} \mathrm{Ba}:{ }^{137} \mathrm{Ba}$ ratio in statoliths of hatchlings reared in water that was enriched with ${ }^{137} \mathrm{Ba}\left(1 \mathrm{\mu g} \mathrm{l}^{-1}{ }^{137} \mathrm{Ba}\right.$ for $\left.2 \mathrm{~d}\right)$ at varying developmental stages. Asterisk indicates significant difference between treatment group and the control group, labels indicate the percent of statoliths successfully marked per treatment, and the broken horizontal line represents the natural ${ }^{138} \mathrm{Ba}:{ }^{137} \mathrm{Ba}$ ratio

\section{Experiment 2: developmental stage}

Hatching occurred over a shorter period than for Experiment 1, with the first individual hatching on 29 October, and the last on 17 November (a hatching period of $20 \mathrm{~d}$ ). A significant difference was detected in mean ${ }^{138} \mathrm{Ba}:{ }^{137} \mathrm{Ba}$ among developmental stages (Table $2 \mathrm{~b})$. However, the only treatment that produced ${ }^{138} \mathrm{Ba}:{ }^{137} \mathrm{Ba}$ that was significantly lower than the control group was the 10 wk development stage (LSD, p $<0.05$; Fig. 3). All other treatments (1, 2, 4 and $6 \mathrm{wk})$ produced ratios similar to that of the control group ( $p>0.05)$. All 10 statoliths from the $10 \mathrm{wk}$ treatment were successfully marked (100\% mark success), and no hatchlings from the remaining treatments were successfully marked (Fig. 3).

\section{DISCUSSION}

Measuring larval dispersal is recognised as one of the greatest challenges facing marine ecologists worldwide (Jones et al. 2005, Sale et al. 2005), and for cephalopods, new methods for unequivocally marking large numbers of hatchlings are essential. Here we show that immersion of eggs in enriched ${ }^{137} \mathrm{Ba}$ is a successful new method of marking large numbers of Sepia apama hatchlings. Each combination of concentration and immersion time produced hatchlings with mean statolith ${ }^{137} \mathrm{Ba}:{ }^{138} \mathrm{Ba}$ values significantly lower than those of control hatchlings, and mark success was generally high (70 to $100 \%$ across all treatments).
The developmental stage at which eggs were immersed was an important determinant of mark success for Sepia apama, with incorporation of ${ }^{137} \mathrm{Ba}$ occurring only at 10 wk of age. Cuttlefish from Experiment 2 hatched 14 to $17 \mathrm{wk}$ after being laid, so individuals from the successful 10 -wk treatment were 59 to $71 \%$ developed at the time of immersion, and immersion for the unsuccessful treatments occurred during the first half of the development period. This result is perhaps unsurprising given that the growth of cuttlefish eggs and embryos is slow during the first half of development, and increases significantly during the latter half (Wachter et al. 1988, Cronin \& Seymour 2000, LacoueLabarthe et al. 2010). The timing of organogenesis for cephalopods is highly species- and temperaturedependent (Boletzky 1983), but is completed by day 32 of the $50 \mathrm{~d}$ development period for $S$. officinalis (Lacoue-Labarthe et al. 2009), and a similar timing of organogenesis for $S$. apama could explain why ${ }^{137} \mathrm{Ba}$ was not assimilated until the second half of the development period. $S$. officinalis embryos exposed to elevated levels of a range of metals (Ag, Co, Cs, Mn and $\mathrm{Zn}$ ) have also been shown to accumulate them in tissues only during the latter $40 \%$ of development, with the second half of development being associated with an increased permeability of the egg capsule to these metals (Lacoue-Labarthe et al. 2008, 2010). Similarly, the oxygen conductance of $S$. apama egg capsules increases gradually in the first half of development, but rapidly in the last 30 to $40 \%$ of the development period (Cronin \& Seymour 2000). Whilst the relationship between egg capsule thickness and its conductance for ${ }^{137} \mathrm{Ba}$ is unknown for $S$. apama, it would be expected that the permeability of the egg capsule to ${ }^{137} \mathrm{Ba}$ would be greatest during the latter 30 to $40 \%$ of development, and this may contribute to a lack of absorption by the embryos during earlier stages. Investigating this effect will be interesting for cephalopods that do not produce eggs enclosed in a capsule (such as Octopus spp.), as ${ }^{137} \mathrm{Ba}$ assimilation may solely be a function of the timing of organogenesis for these groups.

The importance of developmental stage for mark success likely explains the considerable variation seen in the magnitude of the ${ }^{137} \mathrm{Ba}:{ }^{138} \mathrm{Ba}$ shift among individuals immersed at variable developmental stages (Experiment 1) compared to the minimal variation among individuals of the same age (i.e. 10 wk, Experiment 2). Pecl et al. (2010) also found large variation in ${ }^{137} \mathrm{Ba}:{ }^{138} \mathrm{Ba}$ among eggs of 2 multiple spawners (Sepioteuthis australis and Euprymna tasmanica) whose oocytes were probably at a variety of developmental stages at the time of injection with enriched ${ }^{137} \mathrm{Ba}$ during a TRAIL study. The 2 cephalopod species (Octopus pallidus and O. maorum), whose offspring were not successfully marked in that TRAIL study are, like 
Sepia apama, terminal spawners that produce only a single batch of eggs at the end of their life cycle (Pecl et al. 2010). Since determining the maturity status of oocytes externally is generally not possible for cephalopods, marking offspring via TRAIL may be more difficult for species with oocytes of a narrower maturity range, such as terminal spawners. Marking via immersion will often allow the identification of egg developmental stages (albeit qualitatively), as egg capsules and embryos will be visible. Several fish TRAIL studies also found that the timing of isotope injection relative to spawning strongly influences the degree of maternal transfer (Thorrold et al. 2006, Munro et al. 2009). Given the importance of development stage to the success of marking calcified structures, careful consideration should be given to the choice of marking technique (i.e. immersion vs. TRAIL), as different lifehistory strategies are likely to influence the effectiveness of a marking regime.

An advantage of the immersion technique is that quantifying the number of marked individuals will solely be a function of the mark success rate (which will in part be determined by the developmental stage of eggs), as the number of immersed individuals will generally be known. For TRAIL, the number of individuals marked will also be a function of fecundity, and so may be difficult to accurately quantify. For studies requiring quantitative estimates of natal homing, connectivity or rates of dispersal, accurately quantifying the number of individuals successfully marked will be critical, and this may favour the use of immersion techniques for species producing eggs whose development stage can be readily determined.

Whilst not a key focus of this study, it is worth noting that we identified strong peaks in Mn concentration in the nucleus of Sepia apama statoliths. Several studies have found peaks in Mn at the nucleus of fish otoliths (e.g. Brophy et al. 2004, Ruttenberg et al. 2005, Munro et al. 2009, Macdonald \& Crook 2010), but we are not aware of any published studies that have documented this for cephalopods. Brophy et al. (2004) suggested that the peak in Mn concentration does not reflect the external environment of the developing embryo, making the peak a reliable indicator of the otoliths nucleus. Methods of accurately identifying the nucleus of otoliths and statoliths are crucial, as these natal sections are of most relevance for inferences about larval and juvenile dispersal (Ruttenberg et al. 2005). For an early life-history stage mass-marking regime, identifying the natal section of these structures will also be important when checking for the presence or absence of the mark signature.

The various methods of marking and tagging cephalopods and fish (i.e. external visual tags, acoustic telemetry, fluorescent markers, elemental marking via immersion) have contributed substantially to fisheries science in areas such as fish growth, survival, movement, population estimation, stocking, and larval retention and dispersal (Quinn \& Deriso 1999, Semmens et al. 2007, Elsdon et al. 2008, Munro et al. 2008). There are several advantages of marking with enriched isotopes over alternative techniques, (Semmens et al. 2007, Elsdon et al. 2008, Munro et al. 2008, 2009) including the relatively low concentrations required to produce marks relative to other methods (Munro et al. 2008), a lack of stress imposed by the marking procedure (Munro et al. 2009, Williamson et al. 2009b), the large number of individuals that can be marked simultaneously (Thorrold et al. 2006, Pecl et al. 2010), and the wide range of life-history stages that the technique could be applied to (Munro et al. 2008). The significant advances in artificial marking of fishes (including enriched isotopes and fluorescent compounds) have enabled the successful application of chemical massmarking approaches to coral reef fishes (Jones et al. 1999, 2005, Almany et al. 2007); however, a lack of developments for cephalopods has prevented similar field applications for this group. Field application of the immersion technique has strong potential for populations such as the Spencer Gulf Sepia apama breeding aggregation, where a high density of eggs (i.e. several hundred per $\mathrm{m}^{2}$ ) are laid at predictable periods each year in a near-shore spawning ground (Hall \& Hanlon 2002, Dupavillon \& Gillanders 2009). Transporting a large number of egg clusters to a laboratory, exposing them to a $48 \mathrm{~h}$ immersion period (as was sufficient to mark $S$. apama statoliths) and subsequently returning them to the field would certainly be feasible for this population, and would require minimal direct handling of the capsules (eggs are often laid on rocks that can be easily removed from the water at Point Lowly). Similarly high egg densities are common on spawning grounds for several other cephalopods, for example Loligo spp. in the coastal waters of South Africa (Sauer et al. 1997, Hanlon et al. 2002) and California (Hanlon et al. 2004), and the technique could hold strong potential for these populations.

The successful management of cephalopod fisheries is hindered by an inability to evaluate population structure and connectivity (Doubleday et al. 2008a, 2008b, Pecl et al. 2010). Whilst significant advances in recent years have improved our understanding of movement and migration patterns of many cephalopod populations globally (Semmens et al. 2007), methods to tag and track the poorly understood juvenile stage of cephalopods is recognised as a key priority for marine ecologists, as this is the stage most influenced by environmental fluctuations (Semmens et al. 2007). This study, together with the recent evaluation of TRAIL on 4 different cephalopod species (Pecl et al. 2010), will 
hopefully provide the impetus for the application of enriched isotope mass-marking techniques to populations of cephalopods in the field. However, given the species-specific success of TRAIL, further laboratorybased immersion studies should precede field application of mass-marking techniques in different species.

Acknowledgements. Thanks to Jackie Dupavillon for assistance with egg collection, and Edward Snelling for assistance with maintenance of hatchlings. We thank Jonathan Houghton for helpful comments on an original version of the manuscript. Animal use was approved by the University of Adelaide Animal Ethics Committee, and a S115 ministerial exemption (No. 9902133). Financial support was provided by the Field Naturalists Society of South Australia and the Sir Mark Mitchell Research Foundation.

\section{LITERATURE CITED}

Almany GR, Berumen ML, Thorrold SR, Planes S, Jones GP (2007) Local replenishment of coral reef fish populations in a marine reserve. Science 316:742-744

Arkhipkin AI, Campana SE, Fitzgerald J, Thorrold SR (2004) Spatial and temporal variation in elemental signatures of statoliths from the Patagonian longfin squid (Loligo gahi). Can J Fish Aquat Sci 61:1212-1224

Boletzky SV (1983) Sepia officinalis. In: Boyle PR (ed) Cephalopod life cycles, Vol 1: species accounts. Academic Press, London

Boyle PR (1983) Introduction. In: Boyle PR (ed) Cephalopod life cycles, Vol 1: species accounts. Academic Press, London

Brophy D, Jeffries TE, Danilowicz BS (2004) Elevated manganese concentrations at the cores of clupeid otoliths: possible environmental, physiological, or structural origins. Mar Biol 144:779-786

Brown P, Harris JH (1995) Strontium batch-marking of golden perch (Macquaria ambigua Richardson) and trout cod (Macculochella macquariensis Cuvier). In: Secor $\mathrm{DH}_{4}$ Dean JM, Campana SE (eds) Recent developments in fish otolith research. University of South Carolina Press, Columbia, SC

- Campana SE (1999) Chemistry and composition of fish otoliths: pathways, mechanisms and applications. Mar Ecol Prog Ser 188:263-297

Cowen RK, Sponaugle S (2009) Larval dispersal and marine population connectivity. Annu Rev Mar Sci 1:443-466

Cowen RK, Lwiza KMM, Sponaugle S, Paris CB, Olson DB (2000) Connectivity of marine populations: open or closed? Science 287:857-859

Cronin ER, Seymour RS (2000) Respiration of the eggs of the giant cuttlefish Sepia apama. Mar Biol 136:863-870

> Doubleday ZA, Pecl GT, Semmens JM, Danyushevsky L (2008a) Stylet elemental signatures indicate population structure in a holobenthic octopus species, Octopus pallidus. Mar Ecol Prog Ser 371:1-10

Doubleday ZA, Pecl GT, Semmens JM, Danyushevsky L (2008b) Using stylet elemental signatures to determine the population structure of Octopus maorum. Mar Ecol Prog Ser 360:125-133

> Dupavillon JL, Gillanders BM (2009) Impacts of seawater desalination on the giant Australian cuttlefish Sepia apama in the upper Spencer Gulf, South Australia. Mar Environ Res 67:207-218
Elsdon TS, Wells BK, Campana SE, Gillanders BM and others (2008) Otolith chemistry to describe movements and lifehistory parameters of fishes: hypotheses, assumptions, limitations and inferences. Oceanogr Mar Biol Annu Rev 46: 297-330

Ennevor BC, Beames RM (1993) Use of lanthanide elements to mass mark juvenile salmonids. Can J Fish Aquat Sci 50: 1039-1044

Gillanders BM (2002a) Connectivity between juvenile and adult fish populations: Do adults remain near their recruitment estuaries? Mar Ecol Prog Ser 240:215-223

- Gillanders BM (2002b) Temporal and spatial variability in elemental composition of otoliths: implications for determining stock identity and connectivity of populations. Can J Fish Aquat Sci 59:669-679

Gillanders BM, Kingsford MJ (2003) Spatial variation in elemental composition of otoliths of three species of fish (family Sparidae). Estuar Coast Shelf Sci 57:1049-1064

Hall KC, Fowler AJ (2003) Fisheries biology of the cuttlefish, Sepia apama Gray, in South Australian waters. FRDC final report, Project No.98/151. South Australian Research and Development Institute, Adelaide

Hall KC, Hanlon RT (2002) Principal features of the mating system of a large spawning aggregation of the giant Australian cuttlefish Sepia apama (Mollusca: Cephalopoda). Mar Biol 140:533-545

Hanley JS, Shashar N, Smolowitz R, Bullis RA, Mebane WN, Gabr HR, Hanlon RT (1998) Modified laboratory culture techniques for the European cuttlefish Sepia officinalis. Biol Bull 195:223-225

Hanlon RT, Smale MJ, Sauer WHH (2002) The mating system of the squid Loligo vulgaris reynaudii (Cephalopoda, Mollusca) off South Africa: fighting, guarding, sneaking, mating and egg laying behavior. Bull Mar Sci 71:331-345

Hanlon RT, Kangas N, Forsythe JW (2004) Egg-capsule deposition and how behavioral interactions influence spawning rate in the squid Loligo opalescens in Monterey Bay, California. Mar Biol 145:923-930

> Hanlon RT, Naud MJ, Shaw PW, Havenhand JN (2005) Behavioural ecology: transient sexual mimicry leads to fertilization. Nature 433:212

Jones GP, Milicich MJ, Emslie MJ, Lunow C (1999) Selfrecruitment in a coral reef fish population. Nature 402: 802-804

> Jones GP, Planes S, Thorrold SR (2005) Coral reef fish larvae settle close to home. Curr Biol 15:1314-1318

> Kraus RT, Secor DH (2004) Incorporation of strontium into otoliths of an estuarine fish. J Exp Mar Biol Ecol 302:85-106

Lacoue-Labarthe T, Warnau A, Oberhansli F, Teyssie JL, Koueta N, Bustamante P (2008) Differential bioaccumulation behaviour of $\mathrm{Ag}$ and Cd during the early development of the cuttlefish Sepia officinalis. Aquat Toxicol 86:437-446

Lacoue-Labarthe T, Bustamante P, Horlin E, Luna-Acosta A, Bado-Nilles A, Thomas-Guyon H (2009) Phenoloxidase activation in the embryo of the common cuttlefish Sepia officinalis and responses to the $\mathrm{Ag}$ and $\mathrm{Cu}$ exposure. Fish Shellfish Immunol 27:516-521

Lacoue-Labarthe T, Warnau M, Oberhansli F, Teyssie JL, Bustamante $P$ (2010) Contrasting accumulation biokinetics and distribution of Am-241, Co, Cs, Mn and $\mathrm{Zn}$ during the whole development time of the eggs of the common cuttlefish, Sepia officinalis. J Exp Mar Biol Ecol 382:131-138

> Macdonald JI, Crook DA (2010) Variability in Sr:Ca and $\mathrm{Ba}$ :Ca ratios in water and fish otoliths across an estuarine salinity gradient. Mar Ecol Prog Ser 413:147-161

> Minton JW (2004) The pattern of growth in the early life cycle of individual Sepia pharaonis. Mar Freshw Res 55:415-422 
Munro AR, Gillanders BM, Elsdon TS, Crook DA, Sanger AC (2008) Enriched stable isotope marking of juvenile golden perch (Macquaria ambigua) otoliths. Can J Fish Aquat Sci 65:276-285

Munro AR, Gillanders BM, Thurstan S, Crook DA, Sanger AC (2009) Transgenerational marking of freshwater fishes with enriched stable isotopes: a tool for fisheries management and research. J Fish Biol 75:668-684

Naud MJ, Hanlon RT, Hall KC, Shaw PW, Havenhand JN (2004) Behavioural and genetic assessment of reproductive success in a spawning aggregation of the Australian giant cuttlefish, Sepia apama. Anim Behav 67:1043-1050

Payne NL, Gillanders BM, Webber DM, Semmens JM (2010) Interpreting diel activity patterns from acoustic telemetry: the need for controls. Mar Ecol Prog Ser 419:295-301

Payne NL, Gillanders BM, Semmens J (2011a) Breeding durations as estimators of adult sex ratios and population size. Oecologia 165:341-347

Payne NL, Gillanders BM, Seymour RS, Webber DM, Snelling EP, Semmens JM (2011b) Accelerometry estimates field metabolic rate in giant Australian cuttlefish Sepia apama during breeding. J Anim Ecol 80:422-430

Pecl GT, Doubleday ZA, Danyushevsky L, Gilbert S, Moltschaniwskyj NA (2010) Transgenerational marking of cephalopods with an enriched barium isotope: a promising tool for empirically estimating post-hatching movement and population connectivity. ICES J Mar Sci 67: $1372-1380$

Quinn TJ, Deriso RB (1999) Quantitative fish dynamics. Oxford University Press, New York, NY

Rodhouse PG, Nigmatullin CM (1996) Role as consumers. Phil Trans R Soc Lond B 351:1003-1022

Rosman KJR, Taylor PDP (1998) Isotopic compositions of the elements 1997. Pure Appl Chem 70:217-235

Ruttenberg BI, Hamilton SL, Hickford MJH, Paradis GL and others (2005) Elevated levels of trace elements in cores of otoliths and their potential for use as natural tags. Mar Ecol Prog Ser 297:273-281

Editorial responsibility: Matthias Seaman, Oldendorf/Luhe, Germany
Sale PF, Cowen RK, Danilowicz BS, Jones GP and others (2005) Critical science gaps impede use of no-take fishery reserves. Trends Ecol Evol 20:74-80

> Sauer WHH, Roberts MJ, Lipinski MR, Smale MJ, Hanlon RT, Webber DM, O'Dor RK (1997) Choreography of the squids 'night dance'. Biol Bull 192:203-207

Semmens JM, Pecl GT, Gillanders BM, Waluda CM and others (2007) Approaches to resolving cephalopod movement and migration patterns. Rev Fish Biol Fish 17:401-423

Sinclair DJ, Kinsley LPJ, McCulloch MT (1998) High resolution analysis of trace elements in corals by laser ablation ICP-MS. Geochim Cosmochim Acta 62:1889-1901

> Thorrold SR, Latkoczy C, Swart PK, Jones CM (2001) Natal homing in a marine fish metapopulation. Science 291: 297-299

> Thorrold SR, Jones GP, Planes S, Hare JA (2006) Transgenerational marking of embryonic otoliths in marine fishes using barium stable isotopes. Can J Fish Aquat Sci 63: 1193-1197

> Wachter B, Wolf G, Richard A, Decleir W (1988) Regulation of respiration during juvenile development of Sepia officinalis (Mollusca: Cephalopoda). Mar Biol 97:365-371

Warner RR, Hamilton SL, Sheehy MS, Zeidberg LD, Brady BC, Caselle JE (2009) Geographic variation in natal and early larval trace-elemental signatures in the statoliths of the market squid Doryteuthis (formerly Loligo) opalescens. Mar Ecol Prog Ser 379:109-121

Williamson DH, Jones GP, Thorrold SR (2009a) An experimental evaluation of transgenerational isotope labelling in a coral reef grouper. Mar Biol 156:2517-2525

Williamson DH, Jones GP, Thorrold SR, Frisch AJ (2009b) Transgenerational marking of marine fish larvae: stableisotope retention, physiological effects and health issues. J Fish Biol 74:891-905

Zumholz K, Klügel A, Hansteen T, Piatkowski U (2007) Statolith microchemistry traces the environmental history of the boreoatlantic armhook squid Gonatus fabricii. Mar Ecol Prog Ser 333:195-204

Submitted: October 7, 2010; Accepted: May 30, 2011

Proofs received from author(s): August 16, 2011 